\title{
Surgery of diabetic foot in the elderly: early Vs deferred treatment
}

\author{
A Bruttocao ${ }^{1 *}$, C Terranova ${ }^{2}$, B Martella ${ }^{1}$, S Spirch ${ }^{1}$, R Nistri ${ }^{1}$, M Gruppo ${ }^{1}$, F Mazzalai ${ }^{1}$, R Lorenzetti ${ }^{1}$, C Militello ${ }^{1}$ \\ From de Senectute: Age and Health Forum \\ Catanzaro, Italy. 5-7 December 2009
}

\section{Background}

In 1996, the overall prevalence of diabetic patients was 120 million and it will more than double by the year 2025.

The most important complication in these patients is the diabetic foot (sepsis, abscess etc.).

The aim of this study was to assess the role and results of surgery, performed in emergency or deferred emergency, in older population affected by acute septic foot.

\section{Materials and methods}

From 01.01.2004 to 31.12.2008, 100 patients (average age $74.5 \pm 7.3$ ) affected by insulin dependent diabetes complicated by sepsis and abscess of the lower limb were treated in emergency surgery. The inclusion of subjects in the study was considered ethically correct assessment by medical examiner.

61 patients were submitted after a visit to immediate surgical drainage and toilets (group A), while 59 patients were transferred from other departments after an average stay of $6.9 \pm 3.6$ days during which only conservative therapy had been implemented (group B).

\section{Results}

No differences were found between the 2 groups regarding age and clinical features (general conditions, concomitant diseases etc.), except for the following differences in Group B: higher levels of glucose in the blood $(P=0.015)$, lower levels of albumin $(P=0.005)$, and more frequent extension of inflammatory processes to proximal regions of leg $(\mathrm{P}=0.005)$.

The resolution was achieved in group $\mathrm{A}$, without amputation in 13 patients, with amputation of 1 or more toes in 28, with metatarsal amputation in 18 and with Chopart amputation in 2 cases.

Group B: incision and drainage were sufficient only in 4 patients, amputation of 1 or more toes in 21, minor amputations (metatarsal) in 10, Chopart amputations in 20 patients and mayor amputations (leg) in 4 cases.

The level of amputation was significantly more proximal in group B $($ Chi2 $=24.3 \mathrm{P}<0.001)$.

The logistic regression analysis showed a significant relationship between the level of amputation and the number of days elapsed before debridement (odds ratio, 1.61; $\mathrm{P}=0.015$; confidence interval, 1.10-2.36), but not in the presence of peripheral occlusive disease (odds ratio, 1.72, $\mathrm{P}=0.376$; confidence interval, 0.28-15.2).

\section{Conclusions}

In elderly patients with a diabetic foot, the function of the lower limbs is significantly reduced in the case of delayed surgical debridment because of the inflammatory process.

\section{Author details \\ ${ }^{1}$ Clinic of Geriatric Surgery, Hospital University of Padua, Italy. ${ }^{2}$ Unit of Forensic Toxicology and Antidoping, Hospital University of Padua, Italy.}

Published: 19 May 2010

doi:10.1186/1471-2318-10-S1-A46

Cite this article as: Bruttocao et al.: Surgery of diabetic foot in the elderly: early Vs deferred treatment. BMC Geriatrics 2010 10(Suppl 1):A46.

${ }^{1}$ Clinic of Geriatric Surgery, Hospital University of Padua, Italy 